\title{
INTERFERON $\alpha$ EXPRESSION IN THE RAT LIVER AFTER PARTIAL HEPATECTOMY
}

\section{M.M. Perepelyuk, D.B. Fedorchenko, S.L. Rybalko, M.Yu. Obolenskaya}

Institute of Molecular Biology and Genetics,

National Academy of Sciences of Ukraine

150, Zabolotny Str., Kyiv, 03143, Ukraine

e-mail: obolenskaya@imbg.org.ua

Gromashevsky Institute of Epidemiology and Infectious Diseases,

Academy of Medical Sciences of Ukraine

5, Amosov Str., Kyiv, 03680, Ukraine

\begin{abstract}
The current work presents the investigation on IFN- $\alpha / \beta$ expression in rat liver after partial hepatectomy (PHE) and laparotomy $(L A P)$. These operations were used to model the regeneration process and the acute phase response as a component of regeneration process. The relative content of IFN- $\alpha$ in total liver cytosol and IFN- $\alpha$ - and IFN- $\beta$-specific RNAs in total liver RNA were assessed by the biological test and by reverse transcription-polymerase chain reaction, respectively. IFN- $\alpha$-specific $R N A$ and IFN- $\alpha$ protein were shown to be expressed in the intact and regenerating liver.

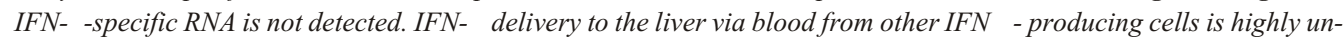
likely due to its negligible concentration in the blood serum. PHE induces the increase of IFN- $\alpha$-specific RNA and protein content during G0/G1 transition of the liver from quiescence to proliferation (1-3 hours after PHE) with the further decrease in their content towards the G1/S transition of hepatocytes (12 hours after PHE). Quantitatively the up-regulation of IFN- $\alpha$ expression was less than maximally possible, which was observed after injection of typical inducer of IFN- $\alpha$ synthesis, poly(I)-poly(C). LAP blocked IFN- $\alpha$ expression completely which was manifested at RNA and protein level in 1, 3, 6, and 12 hours after the operation. Thus, the increase in IFN- $\alpha$ expression at the early phase of regeneration is essential for liver transition from quiescence to proliferation and IFN- $\alpha$ expression is incompatible with the acute phase response. A role of IFN- $\alpha$ in both processes is yet to be defined. The decrease in IFN- $\alpha$ expression till the G1/S transition of hepatocytes in 12 hours is consistent with a widely known concept about antiproliferative activity of IFN- $\alpha$.
\end{abstract}

Keywords: $I F N-\alpha$, liver regeneration.

Authors' interest towards production of endogenous interferon alpha (IFN $\alpha)$ in the course of regenerating

(C) M.M. Perepelyuk, D.B. Fedorchenko, S.L. Rybalko, M.Yu. Obolenskaya, 2006 process and acute phase reaction was conditioned by several factors, namely, wide use of IFN? in medical treatment of malignant tumors, ambiguous nature of its influence at different stages of tumor development, some difficulties caused by use of high doses of IFN? 
and individual character of action. Rat liver after classic surgery of partial hepatectomy (PHE) and laparotomy (LAP) was chosen to be the experimental model.

The decrease in liver functioning as a result of surgical or functional loss of an organ part stimulates the regeneration of its lost mass. All the cells of the organ participate in regeneration process. The liver consists of cells of different origin, namely, parenchymal (hepatocytes) and non-parenchymal (endotheliocytes, Kupffer's cells, Pit-cells, perisinusoidal cells). The hepatocytes are the biggest cells of the organ i.e. they comprise its main mass. These cells are responsible for tissue-specific liver functions, synthesis and secretion of numerous proteins, e.g. albumin, transferrin, blood coagulation factors, ceruloplasmin, transthyretin, transcobalamin, etc. The non-parenchymal cells, though related to performing tissue-specific functions by the organ, still play a very peculiar cell-specific role, they produce numerous mediators, namely, cytokines and eicosanoids, in particular. The mitotic index in intact liver cells is low - 0.001-0.005\% [1].

As a result of mitogenetic stimulation of liver cells they turn from quiescence (in proliferational aspect) towards proliferation. After PHE all liver cells return to cell cycle in series and this process is strictly regulated in time. Hepatocytes are the first ones to start proliferation, i.e. 24 hours earlier than the non-parenchymal cells [2].The period from the start of DNA synthesis is called prereplicative, and it consists of two stages. The first stage (transition from proliferative quiescence towards cell cycle) lasts for 3 hours after PHE. The second one (presynthetical period of the first cell cycle of hepatocytes) lasts for about 12 hours after PHE [3]. Following hepatocytes some other cells proceed to proliferation, namely, bile duct cells, perisinusoidal cells, Kupffer's cells, and finally endotheliocytes [1].

Kupffer's cells activation and the production of the mediators by the latter, TNF $\alpha$, Il-1, Il-6, etc. in particular, are known to be the necessary conditions for proceeding of hepatocytes from proliferational quiescence to cell cycle [4]. Kupffer's cells are capable of producing one more PHE cytokine - IFN $\alpha / \beta$, which has not been studied yet.

As it was shown in the reported before [5], after PHE, a short-term convergence of ribosomes from endoplasmic reticulum (EPR) takes place. The ribo- somes, located in EPR, synthesise secretory proteins, opposite to the ribosomes, located in cytoplasm and producing "housekeeping" proteins. We supposed that temporal convergence of ribosomes from EPR results in short-term decrease in the level of production of specific proteins, i.e. something similar to dedifferentiation takes place. Furthermore, alternated changes of $2^{\prime}-5^{\prime}$-oligoadenylate-synthetase activity in the nucleus and cytoplasm were detected at the early stage of liver regeneration $[5,6]$. Current enzyme is a specific target for IFN $\alpha$ and it can regulate L. RNAase via 2'-5'-oligoadenylates. Beside the mentioned changes, typical for IFN $\alpha$ activity, IFN $\alpha$ can suspend the transcription of some DNA sequences via upstream binding factor (UBF) as well as initiation of the translation by means of phosphorylation of translation initiation factor eIF-2 $\alpha$. On the basis of data (obtained by us and other authors) we made a supposition that IFN $\alpha / \beta$ can take part in dedifferentiation of hepatocytes during their proceeding from proliferational quiescence to cell cycle.

Liver regeneration is a complicated process which includes tissue-specific reactions to liver injury and compensational reactions. Local reaction to injury and systemic acute phase reaction (key role in which is given to liver [7]) belong to the first group; maintaining of essential functions with a lower quantity of cells on the background of reprogramming of the cells and their proliferation heading towards restoration of organ mass and functions belong to the second group [3].

The aim of this work was to determine the level of IFN $\alpha / \beta$ expression in liver, and to define the source of its origin by means of three experimental models. The rats after PHE were chosen to be the model of liver regeneration proper, the rats after LAP were chosen for the investigation of liver tissue-specific reactions to injury of any origin and localization, and the rats after the injection of IFN? inductor - double-strain RNA poly(I)-poly(C) - were chosen for determination of maximum possible level of interferon synthesis in liver. In order to define the source of interferon origin in liver, IFN $\alpha / \beta$ content was determined in spleen and blood serum. The spleen was chosen as the place of maturing and the depot of blood elements, lymphocytes, which produce IFN $\alpha / \beta$, in particular, and the serum was cho- 
sen as the medium for mass transfer and functioning of lymphocytes.

\section{Materials and Methods}

The investigation was performed on the following objects: liver, spleen, and blood serum of intact animals and the animals after $0.5,1,3,6$, and 12 hours of $2 / 3$ liver taken, LAP, and injections of IFN $\alpha$ inductor poly(I)-poly(C). Poly(I)-poly(C) solution was introduced intraperitoneally, $650 \mu \mathrm{g} / \mathrm{ml}, 330 \mu \mathrm{g}$ per rat.

\section{IFN $\alpha / \beta$ content determination}

IFN $\alpha / \beta$ level was determined by the resistance of rat gasserian ganglion neurinoma cells (RGGN) to vesicular stomatitis virus (VSV). 10\%-tissue homogenate in normal saline solution was centrifugated at $3000 \mathrm{~g}$, 20min. Homogenate supernatants and blood serum were treated by $5 \mathrm{~N} \mathrm{HCl}$ to $\mathrm{pH} 2.0$. The majority of proteins, including interferon $\gamma$, are denaturated and and inactivated at this $\mathrm{pH}$ level. IFN $\alpha / \beta$ remain active. Detritus was deposited at $3000 \mathrm{~g}$ for $10 \mathrm{~min}$. Supernatant was neutralized by $5 \mathrm{~N} \mathrm{NaOH}$ to $\mathrm{pH}$ 7.6. RGGN cells suspension, containing $3 \cdot 10^{5} \mathrm{cells} / \mathrm{ml}$, was added by $200 \mu \mathrm{l}$ into 90 wells of 96-well flat bottom tray and incubated at $37^{\circ} \mathrm{C}$, in $5 \% \mathrm{CO}_{2}$ atmosphere, $70 \%$ humidity. In $1-2$ days, when the cells comprised solid monolayer, the culture medium in 70 wells was substituted for cytosol in the series of dilutions $(1: 20,1: 40,1: 80,1: 160,1: 320$, $1: 640,1: 1280)$. In order to control cultures growth and to determine VSV cytopathic dose 4 and 16 wells were used respectively. Further incubation lasted 24 hours, $\mathrm{t}=37^{\circ} \mathrm{C}$, in $5 \% \mathrm{CO}_{2}$ atmosphere, then $100 \mu \mathrm{l}$ of $\mathrm{VSV}$ suspension was added to each of the wells, except the control ones, which corresponded to 100 doses of cytopathic action.

IFN $\alpha / \beta$ quantity was assessed in relative units, which corresponded to the inverse number of cytosol and serum elution that resulted in 50\% decrease in VSV cytopathic effect.

The isolation of RNA by Chomczynski's method [8]

$100 \mathrm{mg}$ of tissue were powdered in a mortar with liquid nitrogen, then put into vial (Falkon), $1 \mathrm{ml} 4 \mathrm{M}$ GTC-buffer (4M guanidine-isothiocyanate, $25 \mathrm{mM}$ Na-acetate, $\mathrm{pH} 7.0,1 \% \beta$-mercaptoethanol) was added for lysis of the cells, passed through the injection needle $(d=0.7 \mathrm{~mm})$ several times for DNA fragmentation. $1 / 10$ volume of $2 \mathrm{M} \mathrm{Na}$-acetate, $\mathrm{pH} 4.0$, equal to water-satu- rated phenol and 1/2 volume of chloroform was added to the homogenate. Vial content was stirred up by a vibration mixer $(15 \mathrm{sec})$, cooled on ice $(15 \mathrm{~min})$, centrifugated at $10000 \mathrm{~g}\left(15 \mathrm{~min}, 4^{\circ} \mathrm{C}\right)$. RNA stays in aqueous phase after centrifugation, while DNA and proteins stay in inter- and phenol phases respectively. Aqueous phase was taken out, equal volume of cooled isopropanol was added and it was placed into refrigerator $\left(-20^{\circ} \mathrm{C}, 1-3\right.$ hours $)$ for RNA precipitation. The mixture was centrifugated for 1 hour at $10000 \mathrm{~g}$, supernatant was carefully taken out and the sediment was flushed twice by ethanol. In the course of $30 \mathrm{~min}$ after centrifugation, ethanol was taken out, the sediment was dried up, and dissolved in tris-EDTA-buffer.

To get rid of phenol residues in RNA solution, 1/10 volume $3 \mathrm{M}$ Na-acetate and 3 volumes of $96 \%$ ethanol were added, then the mixture was stored for the night time at $-20^{\circ} \mathrm{C}$. The mixture was centrifugated at $10000 \mathrm{~g}$ (10min). The sediment was dissolved in water, treated by diethylpyrocarbonate. To store RNA, 1/10 volume of $3 \mathrm{M} \mathrm{Na}$-acetate and 3 volumes of $96 \%$ ethanol was added to the mixture.

RNA concentration was determined by optical density $\lambda=260 \mathrm{~nm}$, and the preparation purity was determined by ratios of $\mathrm{A}_{260} / \mathrm{A}_{280}$ and $\mathrm{A}_{260} / \mathrm{A}_{230}$. All RNA preparations were checked for DNA admixtures by polymerase chain reaction without previous reverse transcription.

\section{Reverse transcription of $R N A$}

Reverse transcription (RT) was performed in $50 \mu 1$. The mixture, containing $12.5 \mu \mathrm{g}$ of RNA, had the addition of $2.5 \mu \mathrm{l}$ of random hexamerous primers (Pharmacia, Sweden) in the concentration of $0.2 \mu \mathrm{g} / \mu \mathrm{l}$ and was incubated at $70^{\circ} \mathrm{C}$ for $5 \mathrm{~min}$ for annealing of primers. Then $5 \mu \mathrm{l} \quad 10 \mathrm{mM} \quad$ of deoxynucleosidetrisphosphate (MBI Fermentas, Lithuania), $10 \mu \mathrm{l}$ of $5 \mathrm{x}$ buffer $(250 \mathrm{mM}$ tris- $\mathrm{HCl}, \mathrm{pH} 8.3$, $250 \mathrm{mM} \mathrm{KCl}, 250 \mathrm{mM} \mathrm{MgCl}, 50 \mathrm{mM}$ DTT) (MBI Fermentas, Lithuania) were added. After 5 min of incubation at $25^{\circ} \mathrm{C}, 2.5 \mu \mathrm{M}$-MuLV of reverse transcriptase (200units/ $\mu \mathrm{l}$ ) (MBI Fermentas, Lithuania) were added, and then incubated for $60 \mathrm{~min}$ at $42^{\circ} \mathrm{C}$. The reaction was stopped by ice-bath cooling.

\section{Polymerase chain reaction (PCR)}

Reaction mixture for PCR, $50 \mu$ in buffer $(10 \mathrm{mM}$ tris- $\mathrm{HCl}, \mathrm{pH} 8.8,50 \mathrm{mM} \mathrm{KCl}, 1.5 \mathrm{mM} \mathrm{MgCl}_{2}$ ) contained 
Fig.1. IFN $\alpha$ content in cytosol of liver, spleen, and blood serum of intact rats

Fig.2. IFN $\alpha$ content in cytosol of liver, spleen, and blood serum after PHE, 1 - liver, 2 - spleen, 3 - serum

$15 \mu 1$ of cDNA solution for the amplification of IFN $\alpha$ or IFN $\beta$-cDNA specific sequences or $5 \mu$ l of cDNA solution for amplification of S12-specific sequence, and 4 nucleosidetrisphosphates in the concentration of $0.2 \mathrm{mM}$ each (MBI Fermentas, Lithuania), 20pM of each of the primers (CJSC Sintol, Russia) and 2.5 units of Taq-polymerase. To avoid mixture evaporating, it was covered by a drop of sterile mineral oil.

The amplification reaction of each of cDNA fragments consisted of previous denaturation $\left(94^{\circ} \mathrm{C}, 4 \mathrm{~min}\right)$, 30 cycles of amplification and final polymerisation $\left(72^{\circ} \mathrm{C}, 7 \mathrm{~min}\right)$. The temperature profiles of the cycles repeated were different for 3 types of fragments. For IFN $\alpha$ and S12-specific fragments it consisted of denaturation $\left(94^{\circ} \mathrm{C}, 1 \mathrm{~min}\right)$, annealing of primers $\left(54^{\circ} \mathrm{C}\right.$, $1 \mathrm{~min})$, synthesis $\left(72^{\circ} \mathrm{C}, 30 \mathrm{sec}\right)$; for IFN $\beta$ it consisted of denaturation $\left(94^{\circ} \mathrm{C}, 1 \mathrm{~min}\right)$, annealing of primers $\left(58^{\circ} \mathrm{C}\right.$, $1 \mathrm{~min})$, synthesis $\left(72^{\circ} \mathrm{C}, 30 \mathrm{sec}\right)$.

Gel-electrophoresis of the amplification products was conducted in 2\%-agarose gel and 1 To determine amplified IFN $\alpha / \beta$-specific products they were precipitated by ethanol from PCR mixture, dissolved and put gel on. To determine the amplified S12-specific product the gel was put on $20 \mu 1$ of PCR reaction mixture.

The results of electrophoresis were visualized using Ultroscan equipment and the pictures were taken by Canon PowerShot A75 digital camera. The densitometry of electrophoregramms was performed using Gel-Pro analysing software.

\section{Results and Discussion}

Determination of IFN $\alpha / \beta$ content in cytosol of liver, spleen, and blood serum

IFN $\alpha / \beta$ of intact animals was revealed in liver and in spleen at 1:160 titre and was not revealed in blood serum (Fig.1).

In the course of prereplicative period after PHE IFN $\alpha / \beta$ contents in liver, spleen, and blood serum are changed differently (Fig.2). In 0.5 hour after PHE, interferon titre in liver increases 4 times (1:640). It remains on the same level for 3 hours and decreases in 6-12 hours.

In 0.5 hour after PHE, the interferon level in spleen increases 4-fold in comparison to intact animals. At the same time IFN $\alpha / \beta$ in blood serum is not determined. Further IFN $\alpha / \beta$ content is detected in blood serum at low titre, which increases insignificantly in 6-12 hours after PHE, while its titres decrease in liver and spleen. It means that PHE stimulates IFN $\alpha / \beta$ synthesis in spleen and liver by means of these organs cells. The weight of the liver after PHE is at least 2 times bigger than that of the spleen, thus it is clear that the major amount of IFN $\alpha / \beta$ is produced in liver, as a result of surgery.

As it was mentioned above, several constituents of liver mass and function regeneration may be distinguished, namely, liver tissue-specific reaction to injury and compensatory reactions for vital functions maintaining. Hence, the question arises - is IFN $\alpha / \beta$ content after PHE determined by reaction to injury and is it specific to acute phase reaction? To answer this 
Fig.3. IFN $\alpha$ content in blood serum, cytosol of liver and spleen of rats after $\operatorname{poly}(\mathrm{U})-\operatorname{poly}(\mathrm{C})$ injection, 1 blood serum, 2 - spleen, 3 - liver

question, IFN $\alpha / \beta$ content after LAP was determined at the same time intervals as after PHE. In 12 hours after surgery, IFN $\alpha / \beta$ level in cytosol of liver, spleen, and blood serum was detected to be lower than the experiment sensitivity. This fact shows that, as a response to injury, IFN $\alpha / \beta$ synthesis in liver and spleen is blocked, and its increased producing after PHE is connected with the restoring constituent of the regenerative process.

To study the issue of how much PHE influences IFN $\alpha / \beta$ synthesis induction, the determination of IFN $\alpha / \beta$ level after specific synthesis inductor (poly(U)-poly(C)) injection was performed. IFN $\alpha / \beta$ producing is detected to be 3 times higher than after PHE (Fig.3). IFN $\alpha / \beta$ content after poly(U)-poly(C) injection in spleen and blood serum differed from after PHE neither in nature nor in quantitative character.

The determination of relative mRNA content, which encodes IFN $\alpha / \beta$, in rat liver after PHE, LAP, and poly(U)-poly $(\mathrm{C})$ injection. In order to assess mRNA content, which encodes IFN $\alpha / \beta$, in liver of intact animals and of the animals after $0.5,1,3,6$, and 12 hours after PHE and LAP the RT-PCR method was used. To select the primers for amplification of cDNA fragments, which encode IFN $\alpha / \beta$ and $\mathrm{S} 12$ ribosomal protein, the matching sequences in NCBI were found. Accession number X00336 corresponds to rat IFNa1 gene and was decoded in [9]. IFN $\alpha$ gene is one of the exceptions among eukaryotic genes as it does not contain introns. Rat IFN $\beta$ cDNA sequence has accession number NM_019127 and was decoded in [10]. cDNA sequence, which encodes S12 protein, was sequenced by Lin et al. [11], NCBI accession number NM_031709.
Both primers and amplification conditions were selected in Vector NTI software. The primers were checked for the capability of forming dimmers and pins. Primers specificity was determined by Blastn software. cDNA primers, which are encoded by rat IFN $\alpha 1$, limit the sequence area to 208 b.p. (from 149 to 356 b.p.). 11 sequences in rat genome are known to be homologous to X00336. Vector NTI software analysis revealed that the primers selected reassociate to IFN $\alpha 1$-specific sequence only and do not interact with any of other 11 IFN-similar sequences. The primers do not interact with cDNA, which encodes IFN $\beta$, the homology to IFN $\alpha$ of which is $40.3 \%$, either. Primers to cDNA, which encode IFN $\beta$, limit the area to 487 b.p. (from 15 to 501 b.p.). The primers to cDNA, which encodes the ribosomal protein S12, were taken from [11]. They limit the area to 367 b.p. (from 90 to 457 b.p.).

In order to perform semiquantitative assessment of the investigated RNA and to avoid technical inaccuracy, the normalisation of optical density indexes of electrophoretic pathways, which produced the amplification products, was performed comparing them to the corresponding index of amplified fragment of cDNA, which encodes S12 ribosomal protein. Usually only one of RNAs, which encode the "housekeeping" proteins, is used for data normalisation. The level of this RNA must be stable. At this condition, the amplified product quantity, produced on the basis of such RNA, will correlate with the quantity of non-fractioned RNA, obtained from RT-PCR reaction. Integral optical density of this product can be used for any not fractioned RNA preparation in order to achieve the normalisation of the investigated indexes (Fig.4). 
Fig.5. Relative content of mRNA, which encodes IFN $\alpha 1$ in rat livers after PHE

mRNA, which encodes IFNa, is detected in liver of intact animals and its current level was accepted as normal. In the course of regenerative process this level decreases in 1 hour after PHE, increases in 3 hours and decreases again in 6-12 hours (Fig.5). Mentioned results correspond to the data obtained on the level of protein and indicate rapid blocking of gene IFN $\alpha$ expression in the course of 12 hours after injury at least.

As we did not differentiate IFN $\alpha$ and IFN $\beta$ producing on the level of protein, it was performed by RT-PCR reaction using special primers for cDNA IFN $\alpha$ and IFN $\beta$. We did not detect fragment amplification products of cDNA, which encodes IFN $\beta$, i.e. corresponding cDNA in preparation of both intact liver and liver after PHE and LAP, as well.

Therefore, after PHE changes detected on the level of protein and RNA concerned the expression
Fig.4. Electrophoregramme of products of S12-specific reaction of RT-PCR of intact and regenerating liver. M - marker, products of RT-PCR reaction of RNA isolated of intact $(1,2)$ and regenerating liver after $0.5(3,4), 1(5,6), 3(7,8), 6(9$, $10)$, and $12(11,12)$ hours after PHE were applied to pathways

of IFN $\alpha$, and not IFN $\beta$. They are specific to regeneration process and, apparently, are less expressed quantitatively due to the other constituent of liver regenerative process i.e. reaction to injury, which is accompanied by blocking the expression of IFNa gene. Significant protein level decrease of IFN $\alpha$ and IFN $\alpha$-specific RNA in 12 hours after PHE does not contradict the common concept on IFN $\alpha$ antiproliferative activity [12]. The data on the factors which regulate IFN? activity in some negative way have recently appeared [13], nevertheless, for specific model, they exist on hypothetic level only [14].

The results obtained are of phenomenological character only. We suppose that regenerative process specific IFN? gene expression is necessary for reprogramming of the cells, possibly, for partial prohibiting protein synthesis, and destructing some RNAs, which functioned actively during G0, by RNAase. IFN $\alpha$ expression stop in liver after LAP points out the role of cytokine as a negative regulator of acute phase reaction.

\section{Conclusions}

IFN $\alpha$ is synthesized in liver cells of intact rats and rats after PHE. IFN $\alpha$ expression in liver of rats after PHE is specific for regenerative constituent of regenerative process, the function of this constituent has not been defined yet. IFN $\alpha$ expression in liver of rats is absent at the initial stage of acute phase reaction. 